\title{
Flexible Specialisation, The New \\ Competition and Industrial Districts
}

Meine Pieter van Dijk

\begin{abstract}
Flexible specialisation, the new competition and industrial districts are concepts reviewed in this article to determine whether they can provide an alternative for the description of the industrial sector as a system of mass production. The concepts mentioned are discussed and criticized in this article. All three concepts stress the importance of a certain division of labour, of interfirm relations, of cooperation (versus competition), of technological development and innovation diffusion, of flexibility, the role of small enterprises and a local value system. However, a number of differences between the concepts are also highlighted, as well as the problems to use them in empirical research. It is concluded that the three terms are complementary and could be used in combination. The 'flexible competitive districts' would provide an alternative type of industrial organization, somewhere between the large scale integrated enterprise and the atomized self-contained individual firm. The challenge lies in turning the positive theory into a normative one. How can industrial development in Eastern Europe and Third world countries be turned into the development of flexible competitive district, which contribute significantly to the development of these countries and allow for an important role for micro, small and medium enterprises? It is argued that this can be done in the framework of urban and regional development policies, but this requires a different role for the government and the provision of an adequate infrastructure.
\end{abstract}

The system of mass production has reached its limits (Storper, 1989). Piore and Sabel (1984) and Best (1990) have convincingly argued that there are alternatives, however. The alternative is producing smaller series of specially designed goods of a specific quality for a niche market, which may command a higher price. In this article we will review three concepts, flexible specialisation, new competition and industrial districts,

Final version accepted on January 25, 1994

Meine Pieter van Dijk

Economic Faculty Microeconomics and Economic Systems

Erasmus University Rotterdam

P.O. Box 1738

NL-3000 DR Rotterdam which have recently come up to suggest an alternative type of industrial organisation between the large scale integrated enterprise and the atomized selfcontained individual firm. The concepts mentioned pretend to describe the present production system better than theories based on the mass production model.

We will present these new concepts, discuss the differences between them and summarize their common characteristics. The aim is to come up with a theory of industrialization providing an alternative for mass production. In this theory small enterprises, networks and clusters and innovation diffusion play an important role. The theory may be particularly relevant for Eastern European and developing countries.

\section{Flexible specialisation}

Piore are Sabel (1984) argue that the history of industrialization has held open one major alternative to the system of mass production, namely craft production, based on the flexible use of general purpose machinery by skilled workers, capable of manufacturing a wide range of products for constantly changing markets. Increasingly segmented markets forced enterprises to follow a strategic approach and to go for specialisation and flexibility. More recent technologies (Alcorta, 1992) also allowed more flexibility, concerning the scale of production. Carlson (1989) also argues for a decrease in the role of scale economies due to flexible production techniques. There is also more flexibility with respect to labour inputs and the type and quality of products produced. Piore and Sabel (1984) use evidence from Japan, West Germany and Italy, where flexible specialised firms are often clustered.

The key elements of the flexible specialisation concept are: 
- Multi-purpose equipment and innovation, skilled labour, with an innovative mentality, uses general purpose equipment to produce whatever is in demand.

- Clusters of enterprises or small firm communities, the seedbed for an exchange of ideas. Physical nearness facilitates the exchange of ideas and it also makes the development of institutions and their interventions more easy and effective.

- Interaction/networking, the whole set of subcontracting relations and collaboration efforts between small enterprises and between smaller and larger ones.

- Collective efficiency, the result of the physical presence nearly of other innovative producers.

Flexible specialisation and small enterprise development can be related in various different ways. Mendez (1991) mentions that in Venezuela the growth of micro enterprises between 1980 and 1988 was part of "a strategy of cost flexibilisation engaged by larger enterprises". This consisted of transferring the cost of an erratic demand to them. He concludes that informalization of the labour force is one of the ways in which the burden of the labour market regulations could be bypassed by these larger enterprises. ${ }^{1}$

Stressing the positive role of small enterprises is one of the strong points of the flexible specialisation concept. It rightly emphasizes the importance of horizontal and vertical links among independent firms. These enterprises may be of different sizes, but they do have a large number of backward linkages with suppliers and forward linkages with clients and cooperate and/or compete with each other regularly. In the case of flexible specialisation two versions can be distinguished, the so called large scale and the small scale variant of Flexible specialisation. In the first case flexible specialisation results from the clustering of small firms and a strong interfirm division of labour. The large firms and a strong interfirm division of labour. The large firm variant exists when large firms decentralise and specialize internally or use specialized suppliers (the Japanese subcontracting system).

An operationalization of the flexible specialisation concept for research in Burkina Faso is summarized in Table I. Field work indicated that
TABLE I

Enterprise level variables for flexible specialisation

\begin{tabular}{ll}
\hline Technology & $\begin{array}{l}\text { Use of multi-purpose equipment and } \\
\text { skilled labour } \\
\text { Indications of product and process } \\
\text { innovations }\end{array}$ \\
Interfirm cooperation & $\begin{array}{l}\text { Subcontracting arrangement } \\
\text { Industrial zones in Ouagadougou and } \\
\text { Clustering }\end{array}$ \\
Bobo-Dioulasso \\
Fetworking & $\begin{array}{l}\text { Formal (for example the Chamber of } \\
\text { commerce) and informal (for example } \\
\text { Lebanese) organisations of business- } \\
\text { men }\end{array}$ \\
Collective efficiency & $\begin{array}{l}\text { The difference in performance } \\
\text { between flexible specialised and other } \\
\text { firms }\end{array}$ \\
\hline
\end{tabular}

flexible specialisation is not yet a strategy of small informal sector type enterprises, but many formal sector industries survived the 80 s by product innovation and increased subcontracting to local small firms. One sixth of the sample of 50 modern industries interviewed could be classified as flexible specialised firms.

\section{The new competition}

Best (1990) describes the present world economy as the New Competition. ${ }^{2}$ At the centre of the new competition is the entrepreneurial firm "an enterprise that is organized from top to bottom to pursue continuous improvement in methods, products and processes" (Best, 1990, p. 2). ${ }^{3}$ The new competition contrasts with the old competition which was based on mass production at the lowest costs. The old competition "was marketcoordinated vertically specialized industrial enterprises" (Best, 1990, p. 7). As will be explained below, the new competition concept is broader than the flexible specialisation concept.

The entrepreneurial firm seeks the competitive edge by superior product design (which may or may not lead to lower costs) and organizational flexibility which manifests itself in a variety of interfirm relations, ranging from groups of small Italian firms linked by cooperative associations for joint marketing, technological advance and financial underwriting to giant Japanese organizational structures coordinating trading companies, banks and manufacturing enterprises (the 
keiretsu). ${ }^{4}$ He stresses the strategic choice amongst organizational forms. There is a mutual dependence between strategy (of the firm) and structure (of the market) (Best, 1990, p. 10). In his book Best describes the organizational variants between the old and the new competition and within the new competition, departing from the firm as a strategic entity. Entrepreneurial firms will try to capture export markets where possible. The emergence of the 'new competition' has taken the United Kingdom and the United States by surprise according to Best.

The new competition is distinguished from the old in four dimensions. The new competition is about strategic action within each dimension, strategic referring to market-shaping activities in contrast with market-reacting responses. The dimensions are:

a) The organization of the entrepreneurial firm: it has a strategic orientation to choose the terrain on which to compete.

b) The coordination across phases of production in the production chain. The choice is not restricted to plan, market or hierarchy, but consultative-cooperative interfirm relations may exist amongst mutually interdependent firms. ${ }^{5}$

c) The organization of the sector is considered very important. ${ }^{6}$ This refers to a variety of interfirm practices and extra-firm agencies such as trade associations, apprenticeship programs, labour education facilities, joint marketing arrangements and regulatory commissions, each facilitating interfirm cooperation.

d) Patterns of industrial policy. According to Best a healthy industrial sector depends upon combining competition with cooperation and this needs to be achieved by policies. Successful industrial policies should help to shape markets, have a production instead of a distributional focus and should be strategically focused.

Best (1990) introduced the new competition concept, pointing at the industrial successes of the Newly Industrialising Countries (NICs) and Japan compared with the lack of such success in the United Kingdom and the United States. The easy explanations of the failure to compete, such as high unit labour costs, heavy government regula- tion of size of the public sector can be contradicted by pointing to the higher unit labour costs in Germany, the fact that Japanese firms are even more regulated and the bigger size of the public sector in Sweden. In the United States the problem of industrial decline is posed wrongly in terms of productivity instead of in organizational terms according to Best (1990, p. 3). Instead he stresses the importance for industrial development of different modes of organisation, of an exportorientation, of flexibility and of conquering niche markets.

Piore and Sabel (1984) mention a number of relevant variables and specify the relations between them. As such the concept of flexible specialisation is somewhat easier to operationalize than the new competition concept. Table II gives the operationalization of the new competition concept used for a comparison between Burkina Faso and Indonesia. It was concluded that Indonesia has embarked successfully upon industrial policies that created the conditions for industrial development of the flexible specialisation and new competition type. Burkina has not yet adopted those policies, although even there some 8 firms in the sample of 50 modern industries could be found which survive by applying these ideas.

Some of the variables mentioned in Table I and

TABLE 11

Operationalization of the new competition concept

Global level indicators: existence of possible export markets and segmentation of these markets, the existence or possible development of niche markets.

National or macro level indicators for the new competition

- share industrial sector in Gross Domestic Product (GDP)

- Growth of industrial sector

- export performance (growth export manufactured goods)

- liberalisation of investment regimes and of financial markets

Firm level variables

Technology: flexible and adaptable

Innovation: like flexible specialisation, but broader, including financial, organisational, marketing, etc. innovations

Interfirm cooperation: All kinds of arrangements, organizational flexibility

Organization of the sector: trade associations, etc.

Vertical disintegration: is taking place

Export-orientation: is built in 
II concerning the firm level require judgement. The classification of enterprises as following the flexible specialisation or new competition approach for our survey data in Burkina Faso may consequently be somewhat subjective. Variables which were not included because they are difficult to measure in a survey are: innovative mentality and the role of trade associations. However, we did classify formal sector industrial enterprises in Burkina Faso on the basis of their technology their innovations, the interfirm relations, the importance of clusters and networks and of skilled labour. For flexible specialisation clustering, networks and the presence of skilled labour were variables specifically included. In the case of the new competition the existence of an export orientation, of catering for segmented markets and of vertical disintegration were taken into consideration as specific variables for the classification. The score for each firm was based on at least one point for technology or innovation (if these were impor$\operatorname{tant}$ ), and one point for the other characteristics mentioned in Tables I and II under firm level variables (if they applied). If the total score was at least three we considered that the enterprise followed the flexible specialisation and/or the new competition approach.

\section{Industrial districts}

The use of the term industrial district goes back to Marshall (1920) who noted that "the advantages of production at a large scale can be as well attained by the aggregation of a large number of small masters into the district as by the erection of a few large works". Krugman (1991) gives a formal version of his theory. Piore and Sabel (1984, p. 265) describe industrial districts as one of the four faces of flexible specialisation. ${ }^{7}$ Interest in the term has revived among others through the research carried out by the International Institute of Labour Studies in Geneva. Researchers of this Institute defined industrial districts as "productive systems characterised by a large number of firms that are involved at various stages and in various ways, in the production of a homogeneous product. A significant feature is that a very high proportion of these firms is small or very small" (Pyke et al., 1990).

Defining characteristics of industrial districts, which come back in the literature (Van Dijk, $1992 \mathrm{~b})$, are: ${ }^{8}$

- nearness of a large number of specialized firms and a strong interfirm division of labour

- a network of entrepreneurs with a similar cultural background, implying collaboration and cooperation

- the presence of small entrepreneurs

- the economies resulting from these characteristics

Pyke et al. (1990) argue that industrial districts should be conceived as a social and economic whole. There are intensive interrelations between the social, political and economic spheres "the functioning of one, say economic, is shaped by the functioning and organisation of the others". The advantage of this interpretation is that the success of an industrial district is not just considered the result of economic and technological factors. They mention adaptability and innovativeness hallmarks of the industrial district and stress the communal capacity to cater for rapidly changing product demands, depending on a flexible labour force and flexible productive networks.

Very often the engine of success has not been the large vertically integrated (multinational) corporation with all its scale advantages and market power. In the Third Italy organisation and leadership came "from small, often family-owned, businesses linked together by an articulated division of specialisation". However, Pyke et al. (1990) also warn that there are big differences between industrial districts. They mention differences in respect of variations in local culture, political allegiances, skill levels, levels of technology, relations between firms and between firms and institutions. Their conclusion is that these differences appear to be much more variations in degree or around common themes rather than differences in essence.

Best (1990, p. 9) considers flexible specialisation a dynamic version of Marshall's industrial district, namely a particular strategy for competitive success that is open to groups of small firms. Best (1990, p. 235) mentions the institutional capacity of industrial districts to continuously learn, adjust, and improve their economic performance. The enterprises in the districts are often 
more innovative in product development, developing production processes and marketing channels. Coordination in a dynamic industrial district is not planned but quasi-spontaneous. But the innovative atmosphere and the entrepreneurial dynamism is certainly part of the secret of the success fo these districts. Flexible productive networks mean that the enterprise can satisfy rapidly increasing demand.

The theory of the firm is a standard part of microeconomic theory. Empirical applications have often taken the form of estimating production functions, taking a black box approach. Recently analytical models have been developed going beyond the black-box conception of a production function and grope for a deeper understanding, based on a contractual view. In their review article of the theory of the firm Holmstrom and Tirole (1989) focus on the limits and the nature of the firm, the financing of firms, the role of management and the internal organization of the firm, to conclude that it is necessary to increase the evidence/theory ratio. A limitation to research at the firm level is not enough, however, to understand the dynamics of the industrial sector. We argued in the case of industrial districts that industry level variables, as well as national and international variables need to be taken into account as well.

\section{Differences between flexible specialisation and new competition}

In Table III the flexible specialisation and new competition concepts are compared on indicators like the assumed objectives of the entrepreneurs, the implied strategy, the assumed market structure and the distinguished modes of organization. A summary is also given of the corresponding government policies.

Flexible specialisation is focusing at the way the firm uses its technology and skilled labour. The new competition looks at the industry, at world wide markets and stresses more the different modes of coordination and organization that are possible in branches where vertical disintegration is taking place. The key variable in flexible specialisation is technology, while the new competition stresses improvements in methods, products and precesses, including the development of new organizational forms and branch organisations, financing arrangements or marketing strategies. Best's definition of innovation is much broader than just a technological innovation.

TABLE III

Flexible specialisation and new competition compared

\begin{tabular}{|c|c|c|}
\hline Indicator & Flexible specialisation & The new competition \\
\hline Objective of firm & Profit and survival in a dynamic market & Profit and a growing share of the market \\
\hline Strategy & $\begin{array}{l}\text { Use technology } \\
\text { A strategy of continuous innovation, } \\
\text { responding quickly to market requirements } \\
\text { Use networks } \\
\text { Target niche market } \\
\text { Benefit from cluster }\end{array}$ & $\begin{array}{l}\text { Strategic behaviour } \\
\text { Pursue continuous improvements in methods, } \\
\text { products and processes } \\
\text { Shape industry sectors and markets: } \\
\text { choose the terrain on which to compete: } \\
\text { market segment }\end{array}$ \\
\hline Market Structure & Medium concentration & Global competition almost full competition \\
\hline Modes of organization & $\begin{array}{l}\text { Large or small scale variant of flexspec with } \\
\text { subcontracting relations }\end{array}$ & $\begin{array}{l}\text { Range of arrangements from stbcontracting } \\
\text { to consultative cooperation }\end{array}$ \\
\hline $\begin{array}{l}\text { Corresponding government } \\
\text { policies }\end{array}$ & $\begin{array}{l}\text { Start innovation centres } \\
\text { Promote subcontracting } \\
\text { Promote clusters of production activities } \\
\text { Creation of an industrial community } \\
\quad \text { (networks) } \\
\text { Combine interfirm cooperation with } \\
\text { competition } \\
\text { Push vocational training }\end{array}$ & $\begin{array}{l}\text { Encourage firms to seek strategic alliances } \\
\text { Help to shape markets by targeting of } \\
\text { strategic sectors } \\
\text { Give a production focus to industrial policies } \\
\text { Promote exports }\end{array}$ \\
\hline
\end{tabular}


Both approaches stress the importance of continuous alertness, the combination of some competition with some collaboration and the advantages of subcontracting relations. Policies in the case of flexible specialisation concentrate on creating clusters and networks and an environment prone to innovation, while the new competition theory stresses the importance of shaping markets and of targeting strategic sectors. Government policies should have a production focus and encourage firms to seek strategic alliances.

\section{Critique on the three concepts}

The flexible specialisation does not take into account the broader context of relevant developments in the world economy, which Best (1990) stresses so much. The flexible specialisation concept has also been criticized because it puts too much emphasis on technology. Finally the concepts suggests that flexible specialisation is the only alternative for mass production. Best (1990) argues that there are more production systems than the flexible specialisation alternative allows for. Flexible specialisation is not the only one single alternative organizational form for mass production. $^{9}$

The new competition concept can be criticized because the new competition does not necessary affect all sectors of the economy. Particularly the traditional non-exporting sectors may be less affected. A second critical remark could be that Best does not explain why all of a sudden the new competition came up. ${ }^{10}$ Finally it is not a theory which is easy to operationalise to find out whether it applies in a given situation (Van Dijk, 1992b).

The industrial districts concept is more a spatial concept, sometimes linked to the joint presence of related industries, or to sectoral specialisation. The industrial district jargon has been used to describe very different situations, ranging from BadenWurttemberg in Germany to Bangalore in India and from the many small industrial districts in the Third Italy to Toyota city in Japan. Secondly some authors claim that industrial districts have come to existence spontaneously and that hence their success may not be repeatable. Finally industrial districts are sometimes discussed in relation to technologically advanced products (for example in Silicon valley and Baden-Wurttemberg) but this does not necessarily have to be the case in many Third world countries. One may wonder whether the industrial district concept really helps us very much. The term is poorly defined, we don't really know what makes an industrial district tick and there is no clear recipe for governments to turn an existing industrial estate into a dynamic industrial district.

For all the three approaches one may ask the question how the analytical concept can be turned into a normative or prescriptive on. Can flexible specialisation, the new competition and industrial districts or a combination of these approaches become a new industrialisation strategy?

\section{Common characteristics of the three concepts}

The flexible specialisation and the new competition concepts both stress the importance of a strong division of labour, interfirm relations, competition and cooperation, innovation, flexibility and a local value system. Table IV brings out the common elements between the three terms.

1. Division of labour. Adam Smith argued

TABLE IV

Common elements in flexible specialisation, the new competition and industrial districts

\begin{tabular}{llll}
\hline Common points & Flexible specialisation & New competition & Industrial districts \\
\hline $\begin{array}{l}\text { Division of labour } \\
\text { Interfirm relations }\end{array}$ & Stressed & Stressed & Stressed \\
$\begin{array}{l}\text { Competition/cooper. } \\
\text { Technological development/ }\end{array}$ & Mix & A whole range & Through nearness \\
$\quad$ innovation & Innovative mentality & Bix & Both \\
$\begin{array}{l}\text { Flexibility } \\
\text { Small enterprises }\end{array}$ & In production & Broader definition of innovations & Facilitates diffusion \\
Value system & Small scale variant & Important role for s.e. & Inherent \\
& Shared & Important & Character: not isolated \\
\hline
\end{tabular}


already that specialisation would lead to economies of scale. ${ }^{11}$ The increasing flexibility, specialisation within the firm and increasing linkages with other firms reflect a more pronounced division of labour. This may lead to important external economies, normally associated with spatial agglomeration, and leading to decreasing costs of production. ${ }^{12}$

2. Interfirm relations. Flexible specialized industries function in a sophisticated network of interfirm relations. Firms generally subcontract to each other and often share knowledge. Jointly they develop new production methods and new products. The new competition stresses the existence of a whole range of arrangements, ranging from subcontracting to consultative cooperation, while flexible specialisation only mentions subcontracting. Licensing agreements, strategic alliances and consultative cooperation are alternative modes of organization gaining importance in the new competition. Best (1990, p. 2) considers the managerial hierarchy an expensive way of coordination, which more often could take place via the market, or through consultative cooperation amongst mutually interdependent firms. This implies that vertical disintegration of large firms makes more sense, instead of further integration of suppliers or sales outlets. ${ }^{13}$

3. Cooperation versus competition. The importance of the particular combination of competition and cooperation is seized by both the flexible specialisation and the new competition concept. The first stresses the importance of clusters and networks to develop these relations, while the second points to the importance of different modes of organization, which may range from subcontracting to consultative cooperation. In smaller enterprises different forms of collaboration can be found. Entrepreneurs may borrow equipment from each other or share important orders. What counts according to all three concepts is the blend of competition and cooperation which promotes the innovative capabilities and competitive efficiency. Interfirm cooperation enables firms to choose how they want to become or remain competitive. Often the low and high road to industrialisation are distinguished, where the low road is based on cheap labour and the high road stresses innovation (Sengenberger et al., 1990, p. 11).

Cooperation has increased, although in many different forms. The number of strategic networks (Jarillo, 1988), long term contracts to supply, reciprocal sales arrangements, cooperation on technology and other forms of cooperative competition have gone up. In the first place the cost of developing new technologies and models has increased tremendously in for example the automobile, lorry and airplane industry. Secondly many big firms have become aware that smaller ones may be better in certain fields Cooperation can be the result of a common background, a mutual interest or the development of a local business community. It is important because it helps to socialise knowledge and to control opportunistic behaviour (Storper, 1989, p. 274).

4. Technological development and innovation diffusion. Competition encourages innovation. According to the flexible specialisation concept the innovative craftsman with his multipurpose equipment brings about the new products of production processes. Best (1990) stresses that innovation can be broader and can be in the design, the marketing, the sales system or organisational form. The claim is that industrial districts facilitate innovation diffusion (Van Dijk, 1992b).

5. Flexibility. In an industrial context flexibility can be defined as the ability to shift promptly from one process and/or product configuration to another and to adjust quantities of output rapidly up or down over the short run. Flexible specialisation stresses this quality and the new competition is also based on this concept. Finally the claim in the case of industrial districts is that there is flexibility because the entrepreneurs can easily interact.

6. The role of small enterprises. The importance of small is stressed particularly by the small scale variant of the flexible specialisation concept. Best (1990) is not very explicit about them, but the different forms of organisation imply a role for small enterprises. Finally in industrial districts one can also distinguish the small scale (the Third Italy) and the large scale (Baden-Wurttemberg) variant.

7. Local value system. All three concepts bring out the importance of shared values. Villaran (1992) stresses that the industrial district is in fact a social network of small and medium firms with an embeddedness in the local culture. Mutual knowledge and trust are often also stressed. 


\section{Previous efforts to stress relations between the three concepts}

Several authors have stressed that the are relations between the three terms. Amin (1992) argues that the principle of flexible specialisation guides successful industrial districts and is appropriate for developing countries. According to Best (1990) flexible specialisation is a dynamic version of Marshall's industrial district: "a particular strategy for competitive success that is open to groups of small firms". Fumagalli and Mussati (1992) formulate in a similar way that the flexible specialisation model includes all the organisational forms like the industrial districts (and so on) which are typical of Italian industrial evolution during the seventies. Finally Ernste (1992) considers flexible specialisation as a new paradigm in industrial geography describing the spatial organisation of the firm. According to him traditional theoretic approaches are not able to explain the current location tendencies in flexibilising industries.

\section{An industrialisation strategy incorporating the three concepts}

Originally import substitution strategies were recommended to Third world countries, suggesting that industrialization could just be copied from the more developed countries and some capital and protection would be all you need. Later exportled industrialization stressed the importance of competition at the world market as a way to become competitive and earn foreign exchange. Recently the flexible specialisation concept stresses that specialisation and flexibility are key elements for industrial competitiveness. The new competition strategy may be considered as an integration of the export-led and flexible specialisation strategy, while the industrial district concepts adds a spatial element to the two concepts.

Industrial development is not just a question of different kind of economies, just like economic development does not just depend on available capital and labour. Porter (1990) stresses that competition can be created. For a city or region the available infrastructure, the presence of skilled labour and the capacity to innovate are for example important marketing factors. For labour learning continues on the job and high skilled labour clusters in or around a limited number of cities (Reich, 1991). The successful industrial districts point to the following factors influencing their success: clustering of activities and the existence of enterprise and entrepreneur networks, flexible specialisation, technological development and innovation diffusion, a strong division of labour and well developed interfirm relations, an important role for small enterprises and the presence of competition and cooperation (Van Dijk, 1992b).

An industrialisation strategy integrating the three concepts could be called creating flexible competitive districts. It would embrace policies by different layers of government and promote a role for private sector institutions. The development of industrial districts and particularly of flexible competitive districts can be encouraged through the following policies which will be discussed briefly below:

- the formulation of national and regional policies

- the definition of a role for different layers of government

- the provision of a good infrastructure.

Much of the literature on developing countries deals with national or regional development problems. It would be very positive for a particular country, city or region if it could develop flexible competitive industrial districts as the engine of growth. Flexible competitive districts may be considered a powerful model of endogenous economic development. The national government would create the macroeconomic conditions for industrial development. The challenge of regional development would be to try to make an industrial district the engine of growth for the region. Regional development planning used to be very much concerned with blue prints and development from above. Nowadays regional governments will try to create an enabling environment for economic activities and have to take into account the conditions which can make an industrial zone a real dynamic industrial district.

Cities are considered as incubators for new economic activities. The external economies are considered very important, particularly for existing small firms and the development of new activities and new firms. According to Storper (1989) 
flexible production might make it possible to break with patterns of extreme metropolitan primacy, because these flexible industries are relatively "independent of the agglomeration economies available in old centres of Fordist (mass production) industry". Industrial districts are often associated with urban industrial sub-systems. Primate and big cities usually have a certain policy and budgetary autonomy to define industrial policies. They may have a better financial basis than regional governments, if the urban tax base is well developed. Their concern is usually just the city, while the regional authorities have to worry about the spread of development.

The original incubator hypothesis states that new firms, because of agglomeration effects, start in the centres of big cities and leave their starting location because of expansion and therefore a lack of space, after a gestation period. De Jong and Lambooy (1986) conclude, however, that the traditional incubation theory is far too simplistic. Techno-economic changes and spatial transformations have led to different patterns. First the external economies can be found in the much wider area of the urbanized territory. Secondly improved infrastructure and communication possibilities have made the factor distance less important. The conclusion is that flexible competitive districts will certainly contribute to regional or urban development. It is more difficult however to tum it around and to make an existing industrial estate part of a dynamic urban or regional development process.

The growth pole concept launched by Perroux is very much related to the discussion of the role of cities as centres with agglomeration economies. Contrary to the industrial district approach these agglomerations are multi-sector phenomena and benefit from specific things like a concentration of inhabitants, a good location and short distances between enterprises. In its practical applications the role of large industries has always been stressed in the case of the growth pole concept.

In regional economics the equity aspect also played an important role. Regional development policies often focused on the weaker regions, regions were many of the attractive points for industrial development were missing. No wonder one has a hard time finding an industrial district in India, where the government has systematically tried to disperse economic activities (Sekhar, 1983). Many of these industries have hardly no forward or backward linkages, but function as large inefficient protected producers and as such would be a refutation of the growth pole theory.

At the end of the eighties regional economic policies in a number of developed countries have changed the emphasis from trying to develop backward regions to fostering the development of certain cities. ${ }^{14}$ It was found that in fact the strongest economic growth often takes place in the suburban areas. Lambooy and Manshanden (1992) explain this development by pointing to the optimal combination of means of communication between these locations. The city generates substantial external agglomeration economies. It facilitates for example information sharing and it attracts traders, suppliers of raw materials and tools and customers. The urban renaissance they observe and consider the consequence of agglomeration economies is also taking place in several developing countries. Cities are the best location for all kind of services, particularly if these services are part of international networks and require certain infrastructural investments. In policy terms this means that such investments would increase the attractiveness of these locations.

\section{The role of different layers of government}

The key question is whether the development of industrial districts in the past has been a spontaneous process or whether it has been triggered off by certain policy measures. How did these centres of high productivity come into existence? Of the examples of industrial districts mentioned some probably developed without special government support, but we still like to stress that the government can help to create the rights conditions for the development of industrial districts. We are certainly not talking about complicated procedures to obtain permissions or about an extensive regulatory framework. Policies to create an enabling environment are required. National, provincial and local government usually can each make a distinctive contribution to the positive policy environment required for a successful industrial district.

If the government creates the conditions the 
private sector should take up the challenge. A very clear division of labour is needed, however, and the government should not act as an industrialist, while the entrepreneurs should not try to do individually what the government can do much better for the whole business community. Can the government, at the national, state (or provincial) or local level do much to develop flexible competitive districts? Most examples of industrial districts mentioned developed without much government support. Unfortunately there is no standardised policy formula of government intervention to create an industrial district, but different levels of government can help to create the enabling environment.

Examples from European show how important industrial policies and industry support institutions have been for the development of a dynamic industrial sector. In Ireland for example a wide range of agencies, usually supported wholly or in part by public funds, assists industry in a variety of ways (O'Farrell, 1986). They help with job creating, training, research and development, exporting, financial assistance and industrial relations. The private sector should develop the necessary technologies and diffuse innovations. the challenge is to link urban development with the insights concerning the development of industrial districts and the useful insights from the flexible specialisation and the new competition approaches.

The challenge for governments is to support entrepreneurship development by creating the right policy environment. An enabling environment helps an entrepreneur to develop his/her business. This is not only a question of the policy environment as has been brought out in the example of Flanders (Donckels and Bert, 1986). Institutions which play an important role are technical schools and vocational training and management centres, financial institutions and technical assistance projects. In some countries entrepreneurship development programs have been launched. Given the central role of technology and innovation in the industrialisation process Innovation centres and Technology diffusion projects also need to be mentioned. ${ }^{15}$ Such policies will usually be initiated by state or provincial authorities.

The urban authorities can create the conditions at the lowest level. They decide about locations, about available space and infrastructure and come up with too many rules and regulations. The challenge is to create an enabling environment. The institutional framework is there, but there is rarely a systematic exchange of ideas with representatives from the private sector on the desired urban development. Chambers of commerce or trade organisations could be used for that purpose. Local interest groups can formulate their desires and these can be channelled to for example the industrial estate authorities (Van Dijk, 1992c).

\section{A good infrastructure}

Porter (1990, p. 544) stresses that economies progress by upgrading their competitive positions: "economic prosperity depends on the productivity with which national resources are employed". The level and growth of productivity can be increased through foreign direct investment, trough trade and through the provision of infrastructure. The latter figures high in plans launched at the end of 1992 by president elect Clinton and by European Commissioner J. Delors. Both use a broad definition of infrastructure, however.

The US Vice-president Al Gore has long favoured the creation of a high speed computer superhighway linking universities, research labs, hospitals, schools and factories (Business Week, July 27,1992 ). Developing countries do not need to go as far as Gore wants to go with a national research-and-education network, digital libraries, an environmental research-and-development program and a larger role for government in creating civilian technology. They certainly need to understand that an infrastructural policy is more than reserving space for industries and building roads to these locations (Van Dijk, 1992c).

In the broad sense improved telecommunication, a good functioning financial system, a network of training centres, a number of related research institutes and of technology developing and diffusion centres are all part of the appropriate infrastructure for industrial development. It is the role of the nation's government to set policies that will provide infrastructure, but this does not mean that the government has to provide it all. Porter (1990) stresses that cooperation between firms through trade associations for the purpose of factor 
creation is desirable. They could set up training centres, operate specialized infrastructure and sponsor university research centres. The government will be more involved in supplying the basic education, power, transportation and telecommunication infrastructure. Improved infrastructure will make it easier for new entrants to come into existing markets and as such it contributes to competition in this way.

\section{Conclusions}

We have learned from the success of South East Asian countries that the role of government has been a different one from what it used to be in many developing country in the seventies. In the first place there is often a close collaboration between the government and the private sector. Secondly the government has a different role at the national (macro economic conditions and a positive climate), the provincial (infrastructure and often education and training) and local level (space and supporting services). Finally governments should promote access by micro, small and medium enterprises to technology, credit and training and be aware of the social costs of the Asian development model.

Economic policy would take the lessons from South East Asia into consideration, including the potential negative effects of this model. The reemergence of micro and small enterprises seems to be a fact and the entrepreneurial strategy of these entrepreneurs is described by the new competition and flexible specialisation concepts. An industrialisation strategy integrating the these concepts and the experience with industrial districts could be called creating flexible competitive districts. It embraces policies by different layers of government and promote a role for private sector institutions. The development of industrial districts and particularly of flexible competitive districts can be encouraged through:

- product specialisation and a pronounced division of labour.

- the development of technology development and innovation diffusion centres.

- reinforcement of existing private sector support institutions and the encouragement of the creation of private sector interests defense organisations like trade organisations.
- facilitating access to vocational training and management training centres for micro and small entrepreneurs and people working in their enterprises.

- promoting access to existing technology development and credit institutions and to industrial estates and pollution equipment which is already installed on these estates.

- promoting horizontal cooperation between micro, small and medium firms.

In these flexible competitive districts mass production would no longer be the rule, rather the exception. They would foster a form of industrial organisation between the large scale integrated firms and the atomized individual firm by devel. oping the economies normally related to large scale production through clustering. Existing examples can be studied further to determine the conditions of success by using the structureconduct-performance paradigm, but by adding typical variables like the relevance of networking, of different forms of organisation, of the degree of innovativeness and of the strategy of conquering niche markets.

\section{Notes}

3 Informalization of the labour force can be the result of four different processes (Mendez, 1991, p.78):

1. The result of a strategy of externalization of the cost function by larger enterprises to overcone a profit squeeze.

2. Informalization of value added by sharing parts of the production process between one large and many micro-enterprises.

3. Informalization of the market, where demand changes in favour of products and services provided by microenterprises.

4. Informalization resulting from introducing new technologies.

2 The term has been used earlier by Bain (1956) and Kotter et al. (1985), but in a different meaning.

3 He distinguishes the entrepreneurial firm from the hierarchical firm of Chandler (1977) and Williamson (1975). Administration in a managerial hierarchy is considered an expensive way of coordination, which more often could take place via the market, or through consuitative-cooperation amongst mutually interdependent firms.

4 Best (1990) stresses institutional pluralism. The same positive result can be achieved through different institutional arrangements. He notably compares different arrangements in Italy, Japan and West-Germany.

5 This is broader than Williamson (1975), who discusses only via the market, or via hierarchies. 
6 Best (1990: p. 17) notes that conventional economics, which sharply divides micro-economics from macro-economic topics obscures a third level of organization crucial to explaining the competitiveness of firms, namely the sector institutions or the extra-firm infrastructure.

7 Industrial districts or regional conglomerations, besides federated enterprises, solar firms and workshop factories.

8 Characteristics which are sometimes mentioned but which are more difficult to use in empirical research are:

- Willingness to work together to resolve clashes of interest

- The widespread entrepreneurial spirit and ability

- Active municipal and local governments

- A local consensus and common values

- The promotion of a social compromise

9 For Best (1990) success will depend on the ability to distinguish between the Japanese corporation and dynamic industrial districts as competitive models and to allow for a comparative assessment of the strength of each.

10 The hypothesis that comes up immediately is the introduction of new technologies (more flexible and computercontrolled equipment), the segmentation of major producer markets and the increased globalisation of the economy due to increased trade and improved communications.

11 Economies of scale occur when the percentage increase in production is higher than the percentage increase in the use of factors of production. Economies of scope are related to advantages of producing several products at the same time, while using the same (marketing, transport, etc.) facilities.

12. Scitovsky (1954) defines pecuniary external economies as follows: if an industry invests and expands it is bound to have pecuniary repercussions on any or all of the following industries: 1 . on industries which produce intermediate goods used by the industry, 2 . through cheapening of its own products, on industries which use these products as intermediate goods and 3 . on industries on whose products factors used by the expanding industry spend their additional income and 4 . on industries whose product is complementary in use to the product produced.

13 Van Dijk and Asselberg (1992) find the same process taking place in the automobile industry in Western Europe. The theory of imperfect markets, of transaction costs and technological developments (in particular lean production and flexible manufacturing) are used to explain disintegration. The effects of economic integration in Europe are analyzed separately.

14 See Lambooy and Manshanden (1992) for the case of the Netherlands.

15 Spath (1992) also gives examples of the ineffectiveness of technology transfer centres in developing countries.

\section{References}

Alcorta, L., 1992, The impact of New Technologies on Scale in Manufacturing Industry, Maastricht: UNU/INTECH.

Amin, A., 1992, 'The Potential for Turning Informal Economies into Marshallian Industrial Districts', Geneva: UNCTAD Conference paper.
Bain, J. S., 1956, Barriers to New Competition, Their Character and Consequences in Manufacturing Industries, Cambridge: Harvard University Press.

Best, M. H., 1990, The New Competition, Cambridge: Harvard University Press.

Chandler, A. D., 1977, The Visible Hand, Cambridge: Harvard University Press.

Carisson, B., 1989, 'The Evolution of Manufacturing Technology and its Impact on Industrial Structure', Small Business Economics 1(1), 21-38.

Carlsson, B., D. Audretsch and Z. Acs, 1994, 'Flexible Technology and Plant Size: US Manufacturing and Metalworking Industries', Internationtal Journal of Indus trial Organization 12(2).

Dijk, M. P. van, 1992a, 'How Relevant is Flexible Specialisation in Burkina Faso's Informal Sector and the Formal Manufacturing Sector?', in J. Rasmussen (ed), Flexible Specialisation: A New View on Small Industry, IDS Bulletin 23(3), 45-51.

Dijk, M.P. van, 1992b, 'The Interrelations between Industrial, Districts and Technological Capabilities Development', Geneva: UNCTAD Conference paper.

Dijk, M.P. van, 1992c, 'Planning Industrial Development in Baluchistan', Quetta: Planning and Development Department Report.

Dijk, M.P. van and G. Asselbergs, 1992, "Vertical Adjustment in the Structure of European Automobile Production', Rotterdam: Growth Dynamics University Institute Discussion Paper.

Donckels, R. and C. Bert, 1986, 'New Firms in the Local Economy: the Case of Belgium', in D. Keeble and E. Wever (eds.), New Firms in Regional Development in Europe, London: Croom Helms.

Ernste, H., 1992, 'Flexible Specialisation and Regional Policy', Nijmegen: Workshop Autonomy and Independent Work.

Fumagalli, A. and G. Mussati, 1992, "The Evolution of Flexible Specialisation Systems, Some Italian Experiences', Nijmegen: Workshop Autonomy and Independent Work.

Holmstrom, B. R. and J. Tirole, 1989, 'The Theory of the Firm', in R. Schmallensee and R. D. Willig (eds.), Handbook of Industrial Organisation, Amsterdam: NorthHolland.

Jarillo, J. C., 1988, 'On Strategic Networks', Strategic Management Journal 9(3), 111-119.

Jong, M. de and J. G. Lambooy, 1986, 'Urban Dynamics and the New Firm: the Position of Amsterdam in the Northern Rimcity', in D. Keeble and E. Wever (eds.), New Firms in Regional Development in Europe, London: Croom Helms.

Kottler, P., L. Fahey and S. Jatusripitak, 1985, The New Competition, Englewood: Prentice-Hall.

Krugman, P., 1991, Geography and Trade, Cambridge: MIT Press.

Lambooy, J. G. and W. J. J. Manshanden, 1992, 'The Renewed West of the Netherlands, from Down-town to Suburbia", The Hague: European cities Conference paper.

Loveman, G. and W. Sengenberger, 1991, 'The Re-emergence 
of Small-Scale Production: An International Comparison", Small Business Economics 3(1), 1-38.

Marshall, A., 1920, Principles of Economics, London: Macmillan.

Mendez-Rivero, D., 1991, Informalization of the Venezuelan Labour Force, The Hague: Institute of Social Studies, Unpublished Phil Thesis.

O'Farrell, P., 1986, 'The Nature of New Firms in Ireland', in D. Keeble and E. Wever (eds.), New Firms in Regional Development in Europe, London: Crooms Helm.

Piore, M.J. and C. Sabel, 1984, The Second Industrial Divide, New York, Basic Books.

Porter, M. P., 1990, The Competitive Advantage of Nations, New York: The Free Press.

Pyke, F., G. Becattini and W. Sengenberger (eds.), 1990, Industrial Districts and Inter-firm Co-operation in Italy, Geneva: International Institute for Labour Studies.

Reich, R. B. 1991, The Work of Nations: Preparing Ourselves for the 21st Century, New York: Vintage Books.

Scitovsky, T., 1954, 'Two Concepts of External Economies', Journal of Political Economy 31(2), 116-142.
Sekhar, A., 1983, 'Industrial Location Policy: The Inóian Experience', Washington: IBRD Working paper.

Sengenberger, W., G. W. Loveman and M. J. Piore (eds.), 1990, The Re-emergence of Small Enterprises: Industrial Restructuring in Developing Countries, Geneva: International Institute for Labour Studies.

Spath, B., 1992, 'The Institutional Environmental and Communities of Small Firms', in I. Rasmussen (ed.) Flexible Specialisation: A New View on Small Industry, IDS Bulletin 23(3), 8-15.

Storper, M., 1989, "The Transition to Flexible Specialisation in the US Firm Industry", Cambridge Journal of Economics $13(1), 17-32$.

Villaran, E. F., 1992, 'Comments', Geneva, UNCTAD symposium on the role of industrial districts in the transfer, adaptation and diffusion of technology.

Williamson, O., 1975, Markets or Hierarchies: Analysis of Antitrust Implication, New York: The Free Press. 